\title{
Estimation Technology and Analysis of the Russian Consumer Sector
}

\author{
Anastasiia Sudakova \\ HSEM, The Ural Federal University named after the first President of Russia B.N. Yeltsin, Ekaterinburg, Russia \\ Email: ae.sudakova@gmail.com
}

\section{Doi:10.5901/mjss.2015.v6n6s4p76}

\begin{abstract}
The article describes the methodology for estimating Russia's consumer sector and the effect of its application. The monitoring procedure of the Russian consumer sector groups indications into two units: estimation of consumer goods and the services market unit. It is worth noting that the state of the consumer sector in the context of its components are evaluated continuously. For example, food safety is evaluated through rate of consumption ( $D$. Olovyannikova), the degree of dependence of the region on food products (A. Kostyaev and Timofeev), common determinant of hunger (EGC), the composite index of household food security (SIPBD). In order to assess the financial condition of these units are taken into account as an integral indicator analysis of the property of organizations and sources of its formation; Analysis of solvency and financial stability; analysis of the financial results of the organization, effective use of assets and sources of their formation, profitability (OE Ivanova, TN Agapov, Logantsova NV). The estimation unit of consumer goods is composed of food products and non-food modules. The consumer goods unit offers two components that provide an estimation of the consumer sector: marketing and production. The results of the estimation show general improvements in the consumer sector in the period 2000-14, but overall development is evaluated as low. The analysis revealed that financing is growing faster than quality indices of development. As an example, financing of agriculture has increased by 1.5 times over 15 years (against comparable prices from 2000), while agricultural production has not changed. Another most pressing challenge is the weak differentiation of the Russian economy, as evidenced by the low rates of non-food production (availability of non-foods of own production remains at a low level and averages $20 \%$ ). The results of the estimation suggest the need to reform the regulation of the sector primarily concerning priorities for its development and improvement of financial and economic mechanisms to achieve them.
\end{abstract}

Keywords: Russian consumer sector, food security, production, final consumption.

\section{Introduction}

The consumer sector plays a leading role in the structure of the economy, providing reproduction of human capital and consuming the bulk of GDP. The ultimate goal for the function and development of any economy is meeting the everincreasing and structurally complex needs of the population. Karl Marx (2011) wrote that "no needs, no production. But consumption reproduces the need".

The main function of the consumer sector is to ensure reproduction of the labor force, the functioning of the family as the fundamental nucleus of society, and investment in human capital. Nobel Laureate Gary Becker (2003) rightly pointed out that "investment in human capital is the main factor contributing to economic growth". Manpower, human knowledge (intelligence), and skills occupy a key place in the reproduction of labor power. The consumer sector (the set of industries consisting of product companies, free-and paid-for services, and households) is a main contributor to public wealth, GDP and its consumption. According to the World Bank, household final consumption accounted for $58 \%$ of the world's GDP in 2001, with $61 \%$ for high-income countries, $68 \%$ for low-income countries, with the Russian share standing at $51 \%$ (The World Bank 2003, 218-221). In Russia, the share of households in the GDP consumption ranged from $45.2 \%$ in 2000 to $56.8 \%$ in 1998; governmental spending on individual goods and services which ranged from $5.9 \%$ in 2000 to $9.3 \%$ in 1997can be added to these (Russian Statistical Yearbook 2003).

The consumer sector is the primary source of economic growth and expanded reproduction. Population growth (the 20th century has seen the world population grow by 4 times, and Russia alone by 2.1 times (World Economy 2003, 499-500), the steady growth of human needs (the law of the rise of needs) and their increasing complexity, as well as growing requirements for the quality of the labor force, necessitate the general trend in capacity expansion and improvement in the quality and range of consumer goods and services, which in turn contributes to the growing demand for productive resources for the sector. If we neglect military aspects of the economy (production of destruction facilities), it is possible to say that economic changes are determined according to dynamics of the consumer sector, complying with the steadily growing human needs. Productivity growth over the 20th century (18.7 times worldwide and 15.4 times in 
Russia) is seen as the main factor of GDP growth over the same period in the world and Russia, at 18 and 6.7 times respectively (470).

In defense of the argument for continued growth in the consumer sector, it is worth noting that the consumer behavior model of the Russian middle class, which accounts for about 55 percent of the population, is similar to consumer behavior in developed countries, and as a result, we can expect a further growth in the domestic consumer market.

Furthermore, those sectors aiming at the consumer market account for two-thirds of Russia's GDP and have generated $80 \%$ of economic growth in the country since 2004.

Nonetheless, the growth of the domestic consumer market is slowing as a result of food embargoes. Sanctions imposed by Russia on imports of food products will cease in August 2015, while European sanctions on Russian companies are expected to be gradually called off in 2015.

Sanctions affect about a quarter of the domestic food market affecting the trend of declining inflation.

Paradoxically, in general, sanctioned imported food products were cheaper than domestic products (milk, cheese, meat products, and fish), and this hindered the growth of prices of domestic agricultural producers and processors (Forecast for the socio-economic development of the Russian Federation 2015).

It is evident that incentives created for Russian agricultural sector have had little beneficial effect, and as a result domestic products are more expensive than imports.

The author believes that the food embargo offers new opportunities for domestic producers to increase market share through expanding sales channels.

The above leads to the conclusion, that the domestic consumer market is rapidly developing, albeit showing heavy import dependence, as evidenced by the imposition of the food embargo in 2014.

In addition, the domestic consumer sector is characterized by such problems as high inflation, low quality of goods and services.

However, a more thorough evaluation of the domestic consumer sector requires taking into consideration all of its components, and an analysis of the existing methods has been carried out in order to assess the components of the consumer sector.

Russian and foreign researchers distinguish four fundamental principles, for instance, to estimate food security (Food security and nourishment. Response to global challenges 2007, 292): availability (food), accessibility (defined mainly through the price level), consumption (rational food process), and stability (security of food supply and quality of products).

The existing body of research offers different thresholds and criteria for food security depending on the methodology, with food security estimated as the ratio of calories consumed, the energy content of the diet, and protein, fat and carbohydrates per person to normal consumption (in Russia the rates are developed by the Institute of Nutrition of RAMS). In this respect, Olovyannikov's method (2009) is worth mentioning.

Kostyaev and Timofeev (2000) chose a different method and offered aggregate and individual consumption indices to estimate food dependence of the regions.

In addition, there are various indices for food security assessment: overall determinant of famines (ODF) (Green revolution 2002), (Global Hunger Index 2009), global hunger index (Global Hunger Index 2011), and composite index of household food security (CIHFS) (Implications of Economic Policy for Food Security 1998).

Food security is also assessed on carry-over or required balance, which is defined differently. For example, security starts from $17 \%$ of total consumption for two months (FAO) and up to $40 \%$ of average annual consumption (United States) (Senchagov V.K. 2005, 286). The ability to provide food from domestic sources of production is considered secure when it is above $80 \%$ (Doctrine of food security of the Russian Federation 2010).

When assessing the consumer sector, it is important to consider the financial performance of the consumer products sector. The problem of developing a system of indicators for a financial analysis of the production sector has been repeatedly set by a number of economists (Ivanova. O. 2013), (Agapova. T. \& Logantseva. N. 2013), (Ivanova, O., 2014), (KPMG 2014). To assess financial performance, the following units of integral indicator are involved: analysis of companies' assets and their sources; analysis of solvency and financial sustainability; analysis of financial statements, efficient use of assets and their sources, and profitability.

In addition, much of the literature concerns assessment of retail markets with such indicators as turnover, market size, estimates of rental payments, needs' identification for retail markets, brand evaluation, and other indicators.

Prior to consumer sector diagnostics, we need to clarify the concept. In the author's earlier publications, the concepts were specified and diagnostic methods were developed. This article is focused on the assessment of the consumer sector, i.e. evaluation of both consumption and manufacturing. 
While the consumer market is considered by the author as a scope of goods and services for final consumers, the consumer sector is supposed to include both the scope of goods and services and the production of consumer goods.

The author has divided the consumer sector into end-use sector (consumer market) and the production of consumer goods, adhering to the classification developed by B. Kuzyk $(2009,591)$, as it is in compliance with the methodology used and seems most complete.

According to this approach, the consumer sector may be classified on several grounds.

Firstly, on the structure of the needs it should meet:

- food - in diverse food products of agriculture, food industry, and private households;

- nonfood products - in clothes, footwear, furniture, household appliances, means of transport and communication, art, medications, etc.;

- life-support services - in health care, housing, welfare, transport, insurance, etc.;

- socio-cultural services- in education, culture, and information.

Secondly, on the structure of those industries required to meet the population's needs:

- agriculture (including private households): crop production, livestock;

- industry: food-processing industry; light industry; medical and pharmaceutical industry; machine-building manufacturing of appliances and personal vehicles; chemical, petrochemical and oil-refining industries producing household chemicals, fuel for private vehicles; building materials, timber and furniture industries manufacturing products for the public;

- construction - housing, utility structures, cottages, garages for the population;

- transport and communication - different types of passenger transportation; communication and telecommunication systems;

- sale of consumer goods;

- personal services, and housing and communal services;

- socio-cultural services: medicine and health; educational institutions; cultural institutions; tourism (inbound and outbound).

As is obvious, all of the sectors mentioned above operate with the purpose of meeting the population's needs, in full or in part.

The object of the research is the Russian consumer sector represented by food and non-food products, sociohumanitarian services, as well as food production (agricultural performance assessment) and non-food products (assessment of light industry performance).

The object of research is the Russian consumer sector, which includes food and non-market goods and services market livelihood and socio-humanitarian services. Evaluation of the consumer sector involves assessment of the manufacturing sector and final consumption.

\section{Methodology}

To carry out consumer sector monitoring, a diagnostic method of assessing the scope of goods and services, with sale and production division, has been applied.

The data obtained as a result of this method initially allow for matching the level of development of Russia's market of goods and services, and subsequently evaluating its impact on the economy and population of the Russian Federation. Finally, it permits economists to define key directions of development of Russia's consumer sector by adjusting existing ones and setting new targets.

In order to assess the market of goods and services in Russia, we suggest an indicative analysis method (Kovaleva. G \& Kuklin. A. 2003), which helps to determine how achieved or projected indicator values comply with the thresholds that meet relevant requirements of social development and sustainable development of the regions of the country, with the consideration of the achieved level and objectives of development.

The method applied here provides diagnostic information about the consumer sector in general, as well as its groups and individual indicators for each subject of the Russian Federation (Figure1). 


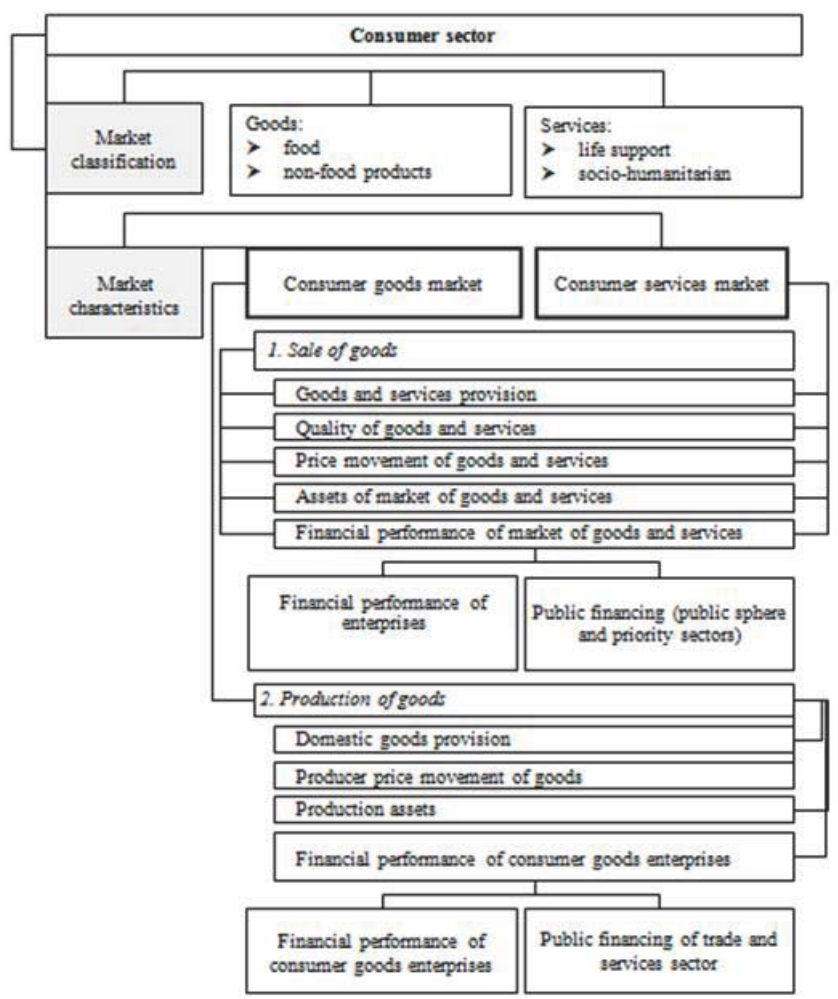

Figure 1. Structure of consumer sector monitoring

To examine the consumer sector, indicative indices grouped into two units are used; namely, the assessment unit of the market of goods and that of the services market.

Each indicative unit includes modules (synthesized indicative figures), which comprise 57 particular indicators estimated from 104 statistical setrs provided by the Federal state statistics service.

The assessment unit of the consumer products is divided into two modules: food and non-food products. The unit of consumer products allows for the evaluation of the consumer sector based on two components: sales (acceptance of retailing by the end user) and production (domestic production of goods).

The assessment unit of the consumer services is also divided into modules: personal services and housing and communal services; transport and communications; health care; education; hotel and restaurant business.

The methodology for assessing the consumer sector is based on a benchmarking analysis (Kovaleva G. \& Kuklin A. 2003), developed by the Ural School of Economics headed by A.I. Tatarkin (member of the RAS), Dr. A.A Kuklin and Dr. A.L. Myzin. This method uses value mapping as a tool to correlate different natural units of indicators with their thresholds.

The identification of thresholds is a separate task. The control set of observations is formed and reviewed for the purpose of objects identification. The tasks of establishing threshold values for indicators and classification of observations are interconnected: to determine thresholds, it is necessary to know the original classification of observations concerning status levels; to classify observations by the status level, it is necessary to know the thresholds of the indicators. As a result, the process of establishing threshold values and classification of observations in the learning sample becomes an iterative process that requires accumulation of databases and knowledge bases (Kovaleva G. \& Kuklin A. 2003). The starting points for thresholds are: the direction of a country's socio-economic development, programs of long-term development of territories, indicators of leading developed and developing countries, international standards of living and quality of life, etc. (Tatarkin A., Myzin A. 2013). 
Thresholds are formed by means of the application of different methods, such as normative, targeted, and expert evaluations.

The following standards of development are introduced in order to analyze the indicators of the Russian consumer sector: high (h), medium ( $m$ ), and low (I). Medium and low standards comprise three sub-levels.

Attribution of territory $j$ (Russian Federation) by the indicator $i$, to any of the levels, is determined by the ratio of $X_{j i}^{t}$ and its thresholds.

All the indicators expressed in named (natural) units are converted into index (normalized) form according to the following ratios:

$$
\left.\begin{array}{l}
\text { if } X_{j i} \geq X_{C 1, j i} \text {, then } X_{j i}^{H}=0 ; \\
\text { if } X_{j i}<X_{C 1, j i} \text {, then } X_{j i}^{H}=\frac{X_{C 1, j i}-X_{j i}}{X_{C 1, j i}-X_{H 1, j i}},
\end{array}\right\}
$$

$X_{j i}$-actual value of index $i$ for territory ${ }^{j}$, expressed in named units;

$X_{j i}^{H}-$ normalized value of index $i$ for territory ${ }^{j}$, expressed in RU;

$X_{C 1, j i}, X_{H 1, j i}$ - thresholds of index ${ }^{i}$ for territory ${ }^{j}$, intermediate between high and middle, middle and low levels respectively, expressed in named units.

According to the ratio (Equations 1), normalized scores (NS) are defined when in the source (named) system of units the reduced indicator values lead to degradation of the system (indicators of 'diminishing' type), and according to the ratio (Equations 2) - if the increased indicator values lead to deterioration (indicators of 'rising' type). For simplicity, the ratios (Equations 1 ) and (Equations 2) omitted the index of a current period of time - $t$.

Table 1 shows classification principles based on normalized values.

Table 1. Classification of consumer sector on indicative indices

\begin{tabular}{|c|c|c|c|c|}
\hline № & Levels & Shortened notation & Normalized indices by thresholds & Scores ${ }_{j i}$ \\
\hline \multirow{2}{*}{ 1. } & High & $\mathrm{B}$ & $X_{j i}{ }^{H}=0,{ }_{j i}{ }^{H} \neq X_{C 1}^{H}$ & 1 \\
\hline \multirow{3}{*}{2.} & \multirow{3}{*}{ Middle } & $\mathrm{C} 1$ & $0<X_{j i}{ }^{H}<X_{C 2}^{H}$ or ${ }^{H}{ }_{j i}{ }^{H}=X_{C 1}^{H}$ & 2 \\
\cline { 3 - 5 } & $\mathrm{C} 2$ & $X_{C 2}^{H} \leq X_{j i}{ }^{H}<X_{C 3}^{H}$ & 3 \\
\hline \multirow{3}{*}{3.} & $\mathrm{C} 3$ & $X_{C 3}^{H} \leq X_{j i}{ }^{H}<1$ & 4 \\
\hline \multirow{3}{*}{ Low } & $\mathrm{H} 1$ & $1 \leq X_{j i}{ }^{H}<X_{H 2}^{H}$ & 5 \\
\cline { 3 - 5 } & $\mathrm{H} 2$ & $X_{H 2}^{H} \leq X_{j i}{ }^{H}<X_{H 3}^{H}$ & 6 \\
\cline { 3 - 5 } & $\mathrm{H} 3$ & $X_{j i}{ }^{H} \geq X_{H 3}^{H}$ & 7 \\
\hline
\end{tabular}

After assessing by particular indicators, assessment by modules, units, and the system in general takes place by means of scores ${ }^{b_{j i}}$. Experiments with different calculations have shown that in this case the calculation of the weighted average normalized estimate is the most appropriate for determining the normalized valuations, and the scores ${ }^{j i i}$ act as balance (Table 1).

$$
\begin{aligned}
& C_{k j}=\left(\sum_{i=1}^{N_{k i}} b_{j i} X_{j i}^{H}\right) / \sum_{i=1}^{N_{k i}} b_{j i}, \\
& C_{j i} \text { - normalized score of indicative module } k \text { for territory }{ }^{j}, \mathrm{RU} ;
\end{aligned}
$$


$N_{k j}$ - number of indicators in module $k$ for territory ${ }^{j}$, units;

$b_{j i}$ - numerical score for assessing indicators.

To assess the status of the unit (synthesized indicators), it is recommended to scale ratings, which makes it possible to reach qualitative conclusions about development (Figure 2).

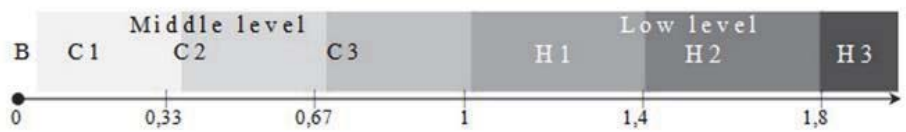

Figure 2. Numerical scores rate against non-uniform scale

The advantages in selecting this methodology can be found in:

1) significantly weaker reliance of results on differences in units of a large number of diverse indicators characterizing the level and quality of the studied object, compared with methods that require the expression of all indicators in common units of measurement;

2) possibility to identify 'weaknesses' through comparison of actual indicator values with their so-called thresholds, corresponding to certain quality levels of status of objects under study. This approach facilitates the task of effective management of agricultural sector and helps identify areas to improve its efficiency.

\section{Results}

An assessment of consumer socio-humanitarian and life-support services should be carried out according to the following: system of health care and social services, education, culture and sports, services of hotel and restaurant business.

Each module includes assessment according to the methodology indicators: availability of service, quality of services, level of prices for services, status of funds and financial performance of the enterprises (organizations).

The sector of socio-humanitarian and life-support services over 15 years has remained at a low level, although the sector has made some insignificant improvements, and in general the normalized score (NS) accounted for $1.736 \mathrm{RU}$ in 2000 and $1.443 \mathrm{RU}$ in 2014 (Figure 3).

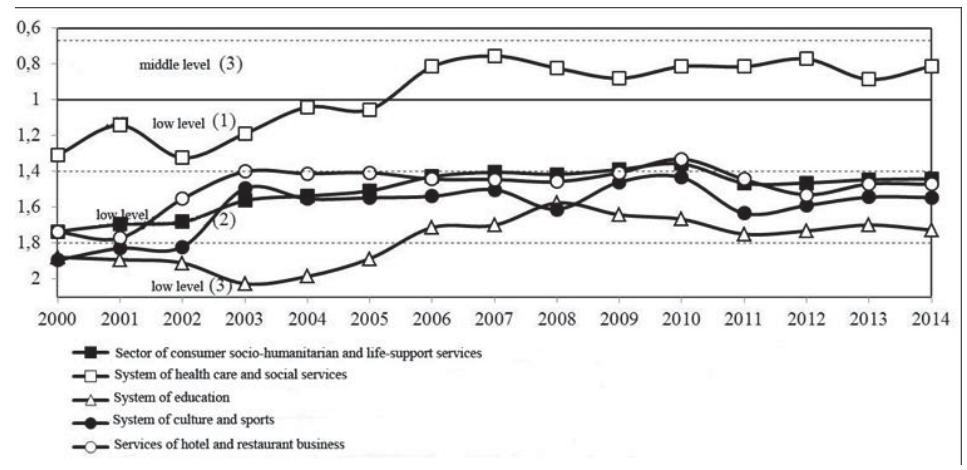

Figure 3. Performance of services sector

The situation in the health system is considered to be the most favourable. The average level of the health system can be viewed through the major private indicators, such as the availability of hospital beds to pregnant and admitted women (on average, 56 beds per1000 persons), supply of doctors (on average, 49 per 10000 persons), supply of medical staff (on average, 107 per 10000 persons).

Private indicators for the entire period under review are less favourable. They include: consumer price index for medical care (on average, 116\% for the analyzed period - current December to December of the previous year), which is 
low by the established thresholds; renovation rate of fixed assets (on average, $4 \%$, low by the established thresholds); fixed capital investments into the health system and social services per person (on average, 301 rub per person in 2000 comparable prices, low by the thresholds).

In addition, the issue of return on investment in the health system also imposes a problem. The cost of financing of health care system increased by 8.7 times over 15 years (in 2000 comparable prices), while the number of physicians increased by 1.5 times, renovation rate by 5 times, fixed assets depreciation increased by 1.5 times, and the reduction in the number of hospital beds per 10000 persons by 1.5 times.

This situation signals the ineffectiveness of government regulation and the need to create a new mechanism.

The least favourable situation in the service sector can be observed in the education system, which level of development is estimated as low.

The following issues remain urgent: structural imbalance in educational attainment (higher-secondary-primary education), inadequate focus of educational institutions on current needs of the national economy, which results in a decrease in the effectiveness of professional education.

Using private indicators, the analysis reveals an increase in the number of higher school students from 2003 to 2008, but since 2008 this indicator has decreased by $20 \%$ (in the following period between 2008 and 2014), as well as number of students receiving specialized secondary education (by 31\% in the period 2000-2014).

It also should be noted that, unfortunately, there is no direct correlation between growth of investment and improvement in quality. Funding for education increased by 3.5 times (in 2000 comparable prices), although the quality has increased only by 0.5 times (NS in 2000 was $2.193 \mathrm{RU}$, in $2014-2.064 \mathrm{RU}$ ).

The analysis illustrates the need for regulatory reform of the education system, particularly in regard to setting priorities for its development and improving financial and economic mechanisms to achieve them.

According to the author's methodology, the food products sector can be assessed by two components: assessment of the status of sale and that of production.

The sale sector evaluates retail trade, i.e. to what extent it is acceptable to the end user. This module provides estimation of the degree of per capita satisfaction of needs for basic agricultural products; quality and prices of food products; funds and financial performance of retailers.

The production sector allows for the evaluation of Russia's food safety and includes such indicators as the availability of basic food goods produced within a territory; consumer price index for agricultural products, agricultural funds; financial performance of agriculture (includes return on goods sold and financing of agriculture from the consolidated budget of the Russian Federation).

Figure 4 shows the food products sector in general and separately for the two modules of sale and production.

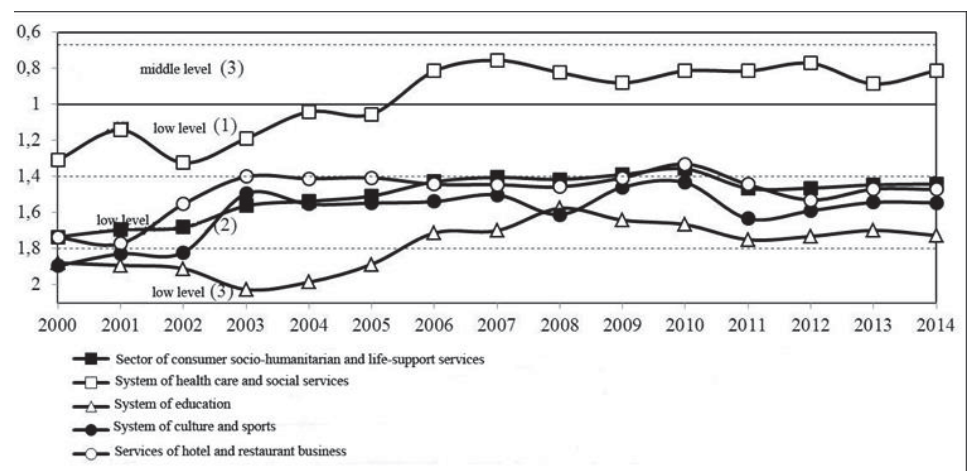

Figure 4. Performance of food products sector

It is evident from the period 2000-14 that the food sector has mainly improved from a low to medium level (change of normalized score (NS) from $1.343 \mathrm{RU}$ in 2000 to $0.858 \mathrm{RU}$ in 2014, or 36\%).

However, the dynamics have not been positive for the whole period. In 2003 and 2004 the food production sector experienced decline (in 2003, change of NS by $9 \%$ against 2002, in 2003/2004 by 4\%), with similar observations made during 2006 and 2008 (2006/2005 - by 8\%, 2007/2006 - by 8.5\%, 2008/2007-3\%) and 2011 (2011/2010 - by 25\%).

Negative dynamics during certain years can be associated with a change in the indicators: 
- deterioration of the quality of food products according to the audits of the Federal service for supervision of consumer rights protection and human welfare in 2004 and 2006 (in 2003 NS was 27.90 RU, in $2004-29.60$ $\mathrm{RU})$, increase in the number of goods of inadequate quality by $6 \%$ in 2004 , as compared with 2003 ; NS was $0.44 \mathrm{RU}$ in 2005 and $0.6 \mathrm{RU}$ in 2006; increase in the number of goods of inadequate quality by $36 \%$ in 2006 with reference to 2005;

- reduction of per capita needs in basic agriculture in 2004, against 2003 (in 2004 NS was 0.451 RU and 0.395 $\mathrm{RU}$ in 2003), decrease in the level of satisfaction by $1 \%$;

- significant increase in food prices in 2004, 2007, 2008, 2010, 2012 and 2014. In 2004, CPI was higher by $2 \%$ as compared with 2003 (hereinafter referred to as 2003-2004), in 2006-2007 by 7\%, in 2007-2008 by 1\%, in $2009-2010$ by $6.8 \%$, in $2012-2011$ by $2.5 \%$, and in $2014-2013$ by $8 \%$.

So, negative dynamics of indicators in the sector of food production are observed in 2003, 2007-2008 and 2011, and can be explained by the change in the following private indicators: reduction in funding, rise in consumer price index, decreased profitability of the sold goods (works, services) of agricultural enterprises.

Russia experienced reduced financing of agriculture up to 2012, for instance by 23\% in 2002, with respect to 2001 (in 2001 NS was 1.782, in $2002-1.84$, by 13.5\% in 2010 with respect to 2009).

A case in point is the analysis of agricultural production output and public funding for agriculture. From 2000 to $2005,31 \%$ cost reduction is observed for one ton of agricultural products ${ }^{1}$ (in comparable prices), however, from 2005 to 2014 , the cost has risen by $104 \%$. The minimum cost of one ton of agricultural products (in 2000) amounted to 268 thousand roubles, and the maximum cost - 548 thousand roubles (in 2000). From 2000 to 2014, the cost of one ton of agricultural products (in 2000) grew by $76 \%$, while in natural units the whole output accounted for $23 \%$.

The author believes that these dynamics can mainly be explained by the growth of transaction costs and corruption, and in a less degree by the decline in yields.

It is worth noting that the degree of availability of basic food products manufactured within the territory has remained at a high level throughout the period.

The consumer goods sector is estimated being similar to the food products sector according to two modules - the sale sector and production sector.

Figure 5 provides data on the non-food products sector as a whole and separately on the sale and production sectors.

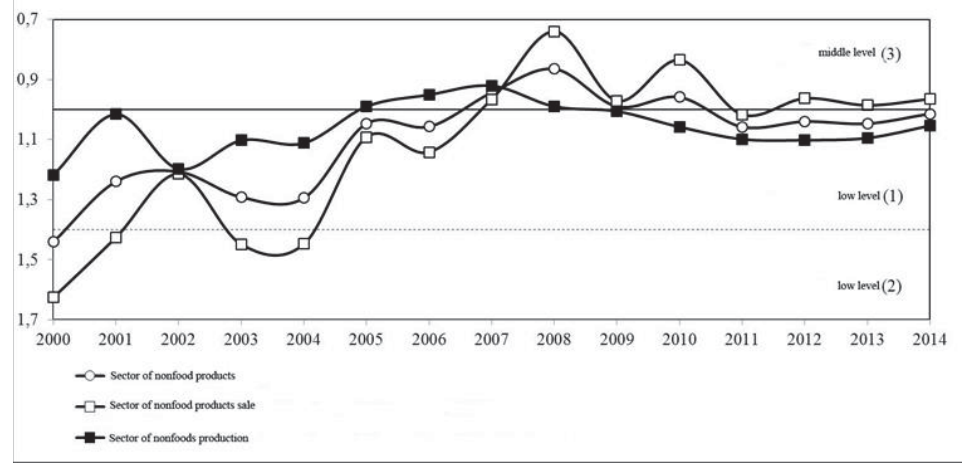

Figure 5. Performance of non-foods sector

In general, the sector shows an up-turn from low to medium over the analyzed period (in 2000 NS was 1.441 RU and 1.014 RU in 2014).

However, such positive dynamics are not observed everywhere, for instance, the sale of non-food products sector demonstrates decline in 2003, 2006, 2009, and 2011 due to the change of private indicators, such as $21 \%$ deterioration in the quality of goods in 2003 as compared with 2002 , by $2.5 \%$ in $2006 / 2005$, by $7.5 \%$ in $2009 / 2008$, and $64 \%$ reduction of profitability of the sold goods in 2003/2002, by $45 \%$ in 2009/2008 and 2011/2010.

1 One ton of agricultural products amounts to production of crops, potatoes, milk and dairy products, vegetables, eggs, meat and meat products in dead weight 
The sector of non-food production demonstrates a less advantageous picture and is assessed as being at a low level. This is caused by moderate output and insignificant financial support. Financing of this sector's development is from Russia's consolidated budget and since 2008 this has included light industry. Over the period of 2008-2011, it went up from 252 million roubles to 1,817 million roubles, however, since then there has been a gradual decline, compounded by a high degree of depreciation of basic production assets. $20 \%$.

With regards the availability of household goods of own production, the indicator remains fairly low, on average, at

This situation in the sector of consumer goods production is associated with low differentiation of the Russian economy.

On the whole, the state of things in the sector of nonfood production is caused by a low differentiation of the Russian economy.

\section{Conclusion}

Results of the estimation, made in line with the author's methodology, show that in general the consumer sector improved its status over the period 2000-2014, however, the overall development level is assessed as low.

The sectoral analysis revealed that funding increased more rapidly than did the quality of development. For example, financing of the agricultural sector over 15 years grew 1.5 times (in 2000 comparable prices), while volume of agricultural output remained unchanged. With 3.5 times increase in financing of education, its quality indicator increased only 0.5 times (NS made up $2.193 \mathrm{RU}$ in 2000 and $2.064 \mathrm{RU}$ in 2014).

The low differentiation of the Russian economy imposes another pressing challenge, as evidenced by the low rates of non-food production (availability of non-foods of own production remains at a low level and averages 20\%).

This demonstrates the need to reform regulation of the consumer sector, especially in setting priorities for its development and improving financial and economic mechanisms to achieve them.

\section{Acknowledgements}

The author gratefully acknowledge the assistance of the Seniour lecture chair of linguistics and professional communication in foreign languages ISPS of The Ural Federal University, namely Kocheva Olga, in preparation this text for publication.

\section{References}

Agapova. T. \& Logantseva. N. 2013. Integral estimates of safe performance of rural areas (Integralnaia otsenka bezopasnosti funktsionirovaniia selskikh territory). Issues of regional economy. N 4 (17). pp. 3-8.

Doctrine of food security of the Russian Federation, validated by the RF President's decree of 30.01.2010 N 120. Accessed: September 17, 2015: http://www.consultant.ru/online/

Economic security of Sverdlovsk oblast. Ed. by Kovaleva G \& Kuklin A. Ekaterinburg: URGU, 2003. pp.455.

Food security and nourishment. Response to global challenges. 2007. International Weiterbildung gGmbH. Capacity Building International. Germany.

Forecast for the socio-economic development of the Russian Federation for 2015 and the planning period of 2016 and 2017 (developed by Ministry of economic development of Russia). Accessed: September 7, 2015. http://www.consultant.ru/document/cons_doc_ LAW_169269/?frame=14

Gary S. Becker. 2003. Human behavior. The economic approach. Moscow: GUVSHE.

Global Hunger Index. Accessed: September 17, 2015. http://www.ifpri.org/publication/2009-global-hunger-index

Global Hunger Index. The Challenge of Hunger: Focus on the Crisis of Child Under nutrition. 2011. Accessed: September 17, 2015. http://www.bread.org/event/gathering-2011/international-meeting/pdf/2010-global-hunger-index.pdf

Green revolution: Curse or Blessing? 2002. Accessed: September 17, 2015. http://people.forestry.oregonstate.edu/steve-strauss/sites/ people.forestry.oregonstate.edu.steve-strauss/files/GreenRevo-Curse-or-Blessing-IFPRI.pdf

Implications of Economic Policy for Food Security: A Training Manual. 1998. Rome. Accessed: September 17, 2015. http://www.fao.org/ DOCREP/004/X3936E/X3936E00.HTM

Ivanova. O. 2013. Analysis and forecast for the development of Russia's production sector (Analiz i prognoz razvitiia promyshlennogo sektora Rossii). Science and business: paths of development. N 10 (28). 88-91.

Ivanova. O. 2014. Administration rating of industrial sector spending on the basis of integral indicator (Otsenka upravleniia zatratami promyshlennogo sektora ekonomiki na osnove integralnogo pokazatelia). Proceedings of Moscow University at the Ministry of Home Affairs of Russia. N 3. pp. 146-151 
Kostiaev, A. \& Timofeev, M. (2000). National and regional food security (Natsionalnaia i regionalnaia prodovolstvennaia bezopastnost). Regional economy: stabilization and development. Proceedings of the research works. Vol.1. M. VNIETUSH. 500-517.

KPMG, 2014. Prospects for the world industrial sector: estimates of efficiency of businesses (Perspektivy mirovogo promyshlennogo sektora: otsenka effektivnosti raboty predpriiati). Accessed: September 17, 2015. http://www.kpmg.com/RU/ru/lssuesAnd Insights/ArticlesPublications/Documents/S_GMO_1r.pdf

Kuzyk B. 2009. Forecasting, strategic planning and national programming. Moscow: Economika.

Marx. K. 2011. Capital: A Critique of Political Economy: Vol. 1. Trans. from German, French, English. Moscow: EXMO.

Oloviannikov. D. 2009. Assessment methodology of regional food security on the example of Republic of Buryatia (Metodika otsenki sostoianiia prodovolstvennoi bezopastnosti regiona na primere Respubliki Buryatia). Proceedings of Irkutsk State Economics Academy. 2009. N3. 60-63.

Russian Statistical Yearbook. 2003. Collection of statistics. Moscow: Russia's Goskomstat.

Senchagov V.K. 2005. Economic security of Russia: General course. Moscow: Delo.

Tatarkin A., Myzin A. 2013. Status simulation of national wealth of Russia's regions (Modelirovanie sostoianiia natsionalnogo bogatstva regionov Rossii). Economy of the region. N 4. pp. 53-65.

The World Bank. 2003. World Development Indicators 2003. Pp. 218-221.

World Economy. 2003. Global trends for 100 years. Moscow: Economist. Pp. 499-500. 